\title{
A prática docente na Educação de Jovens e Adultos: construindo novas possibilidades
}

\author{
The teaching practice in Young and Adult Education: building new possibilities
}

\author{
Diego LUTZ* \\ Aline Reis Calvo HERNANDEZ**
}

\begin{abstract}
RESUMO: $O$ presente artigo tem por objetivo refletir sobre a possibilidade de novas práticas na Educação de Jovens e Adultos, apontando para novos horizontes para esta modalidade de ensino. Esta reflexão teve como ponto de partida a prática de Estágio, no curso de Licenciatura em Pedagogia a Distancia da Universidade Federal do Rio Grande do Sul. A realidade da EJA no país nos mostra que, embora seja uma modalidade diferente da educação regular, as práticas ali estabelecidas refletem velhas práxis docentes centradas no conteúdo, sem considerar os sujeitos, sua história, sua realidade e necessidades. Neste sentido, a partir do trabalho desenvolvido com a metodologia dos Projetos de Aprendizagem (PA), considerando os sujeitos como foco central da prática docente, buscou-se transformar o espaço da sala de aula em um ambiente dinâmico, de interação, de práticas colaborativas e aprendizagem,

ABSTRACT: This article aims to reflect on the possibility of new practices in Youth and Adult Education, pointing to new horizons for this type of teaching. This reflection had as its starting point the practice of Internship, in the Distance Education Degree course at the Federal University of Rio Grande do Sul. The reality of EJA in the country shows us that, although it is a different modality from regular education, the practices established there reflect old teaching praxis centered on the content, without considering the subjects, their history, their reality and needs. In this sense, based on the work developed with the Learning Projects (PA) methodology, considering the subjects as the central focus of teaching practice, we sought to transform the classroom space into a dynamic environment, of interaction, of collaborative practices and learning, exploring school spaces and information and communication technologies.
\end{abstract} explorando os espaços escolares e as tecnologias da informação e de comunicação.

KEYWORDS: Young and Adult Education. Empowerment. Learn.

PALAVRAS-CHAVE: Educação de Jovens e Adultos. Empoderamento. Aprender.

\section{Introdução}

Este artigo tem por objetivo apresentar e refletir sobre a prática de Estágio Supervisionado ${ }^{1}$ do curso de Licenciatura em Pedagogia a Distância (PEAD) da Universidade

\footnotetext{
* Doutorando em Educação no Programa de Pós-Graduação em Educação da Universidade Federal do Rio Grande do Sul (UFRGS), https://orcid.org/0000-0002-8540-0905, diegolutz@ hotmail.com.

** Pós-Doutora em Psicologia Social (PUC/RS), Professora Adjunta da Faculdade de Educação da Universidade Federal do Rio Grande do Sul (UFRGS), Líder do grupo de pesquisa Psicologia Política, Educação, Memórias e Histórias do Presente (POLEMHIS/CNPq), https://orcid.org/0000-0001-5413-319X,
} alinehernandez@hotmail.com.

${ }^{1}$ Realizado no segundo semestre do ano de 2018. 
Federal do Rio Grande do Sul (UFRGS), realizado numa escola pública estadual, localizada no bairro Sarandi, no município de Porto Alegre, motivada a partir de estudos da Interdisciplina Educação de Jovens de Adultos no Brasil, decorrendo de uma necessidade de aperfeiçoamento da práxis pedagógica enquanto docente. O objetivo do PEAD reside no aperfeiçoamento de profissionais em formação contínua, refletindo sobre as práticas e desafiando-os a repensá-las, buscando a participação dos estudantes enquanto protagonistas no processo de construção do seu conhecimento, mediados pelo uso das tecnologias da informação e comunicação (TIC).

De acordo com o definido na legislação vigente, a Educação de Jovens e Adultos (EJA) é uma modalidade de ensino destinada àqueles que não tiveram acesso ou continuidade de estudos nos ensinos fundamental e médio na idade própria e constituirá instrumento para a educação e a aprendizagem ao longo da vida (BRASIL, 2018). Além disso, a mesma legislação aponta que a oferta da EJA pelos sistemas de ensino deverá propiciar oportunidades educacionais apropriadas, considerando as características dos sujeitos que a frequentam, bem como seus interesses, condições de vida e trabalho (BRASIL, 2018), entre outros.

Friedrich (et. al. 2010, p. 405) destaca que:

[...] Uma reflexão sobre a educação aponta para a educação de adultos como resultado da ineficácia do Estado em garantir, por meio de políticas públicas adequadas, a oferta e a permanência da criança e do adolescente na escola. Sendo assim, as iniciativas em EJA, em sua grande maioria, caminham na marginalidade do processo educativo brasileiro e as questões mais incisivas no tocante a esta afirmação dizem respeito às propostas de governo criadas de acordo com as necessidades políticas de cada sistema ideologicamente dominante.

Cumpre destacar que é dever do poder público propiciar o acesso à EJA, estimulando a permanência do aluno trabalhador na escola, estabelecendo um conjunto de ações integradas que permitam que isso ocorra. Na prática, se observarmos a oferta na EJA no país, podemos apontar uma realidade que caminha na contramão da legislação, principalmente no que diz respeito às condições e à forma como ela é ofertada.

Friedrich (et. al. 200, p. 405) lembra que

[...] Não se pode refletir sobre a Educação de Jovens e Adultos sem relacioná-la diretamente à forma como a sociedade está estruturada. Os cursos de alfabetização de adultos existem, exatamente, pela falta objetiva de 
oportunidades educacionais que garantam às crianças o acesso à escola, bem como à sua permanência, haja vista os altos índices de evasão e repetência evidenciados nas estatísticas sociais.

Hara (1992) pontua, ainda, que várias dificuldades concernentes à Educação de Jovens e Adultos estão no cerce desse processo, que envolvem desde a prática docente que não considera os saberes e experiências dos sujeitos ali presentes e, ainda, das enfrentadas pelos adultos, seja de trabalhos exaustivos, condições sociais etc. A autora destaca ainda que, em muitas situações de ensino na EJA, as práticas estão centradas em cópias, leituras de textos didáticos que não dialogam com a realidade de jovens e adultos ou não despertam interesse, atividades repetitivas etc. Hara (1992) alerta sobre os desafios de trabalhar com jovens e adultos na EJA, principalmente no que se refere à motivá-los e engajá-los ao processo escolar. Para a autora, se trata de um desafio de ordem política, que exige que a prática docente possibilite aos estudantes que se reconheçam como sujeitos, com sua identidade, pertencimento a uma realidade e com história própria.

Muitas vezes, os conteúdos programáticos são apresentados sem ancoragens com as experiências pessoais, familiares e profissionais desses estudantes e na dimensão didática, envolvem práticas "infantilizadas" aprendidas nos cursos de graduação em Pedagogia voltados à Educação Infantil e Anos Inicias, pouca exploração de temas transversais (direitos humanos, diversidade, trabalho, gênero e sexualidade) que despertam interesse desse público alvo e são concernentes ao desenvolvimento de muitos conteúdos. As metodologias e avaliações padrão - para toda a turma - sem atentar para as especificidades e níveis de leitura, escrita e outras competências presentes na heterogeneidade de uma turma de EJA também podem ser fatores agravantes ao processo de ensino. Em muitos casos, a EJA acaba tornandose uma cópia do ensino que já era ofertado na escola regular, com práticas tradicionais, transmissão de conteúdos, desconsiderando os sujeitos que ali estão.

Com relação à formação de professores para atuar na EJA, Paiva e Fernandes (2016) discutem que os Cursos de Graduação em Pedagogia do país têm enfoque, prioritariamente, na Educação Infantil e Anos Iniciais não desenvolvendo competências docentes específicas à atuação na EJA, sem aprofundamento nas especificidades de seu público-alvo e didática proópria. Assim, muitos docentes da EJA aprendem na prática e mediante formações continuadas.

[...] Sujeitos de direito, portanto, permanecem interditados da escolarização, e esta, quando ofertada, esbarra nos limites de uma formação precária e 
insuficiente de professores, do ponto de vista dos fundamentos epistemológicos e teórico metodológicos que atendam especificidades e necessidades do público jovem e adulto. (PAIVA, FERNANDES, 2016, p. $30)$.

Os sujeitos que frequentam a EJA são distintos, de realidades diversas, sendo que, muitas vezes, a educação escolar não é a sua prioridade, haja vista as dificuldades pelas quais passam. Por isso, a necessidade de tornar a prática um ato político, constitutivo dos sujeitos, como ferramenta para seu desenvolvimento. Friedrich (et al., 2010, p.406) lembra que:

[...] Com um público específico que traz consigo sequelas de experiências frustradas ao longo da vida, o adulto chega à EJA com uma bagagem cultural diversificada, habilidades inúmeras, conhecimentos acumulados e reflexões sobre o seu mundo. Muitos se encontram humilhados pela condição de excluídos da escola por diferentes razões: necessidade de trabalho, reprovações sucessivas, por não se terem adaptado às normas da escola, por não terem conseguido aprender o necessário para sobreviver neste mundo científico e tecnológico em que vivem. Chegam e encontram a mesma escola que os excluiu há anos com propostas pedagógicas que não contemplam as suas expectativas e escolas com regras específicas e generalizadas. Este, além de outros aspectos leva ao alto índice de evasão observada nos programas de EJA na atualidade. Esse fracasso pode ser explicado, principalmente, por problemas de concepção epistemológica e pedagógica entre o concebido pelas propostas oficiais e o vivido por esta comunidade no âmbito escolar.

Muitos desses aspectos foram encontrados na turma em que foi realizado o estágio, em uma classe de Anos Iniciais, em turma unidocente, cuja prática pedagógica em curso não considerava a realidade dos educandos e as ações propostas eram desconexas de suas realidades e necessidades, a taxa de frequência era muito baixa, além de muitos alunos oriundos das classes regulares apresentarem histórico de reprovações. Neste sentido, é preciso que a

[...] EJA mostre plenamente seu potencial de educação permanente relativa ao desenvolvimento da pessoa humana face à ética, à estética, à constituição de identidade, de si e do outro e ao direito ao saber. Quando o Brasil oferecer a esta população reais condições de inclusão na escolaridade e na cidadania, os "dois brasis", ao invés de mostrarem apenas a face perversa e dualista de um passado ainda em curso, poderão efetivar o princípio de igualdade de oportunidades de modo a revelar méritos pessoais e riquezas insuspeitadas de um povo e de um Brasil uno em sua multiplicidade, moderno e democrático. (BRASIL, 2000, p.67).

A escola estadual onde foi realizado o estágio está situada no bairro Sarandi, um dos maiores do município de Porto Alegre. Atende ao Ensino Fundamental completo, sendo que 
durante o dia, oferta regular e, à noite, a modalidade EJA. A turma onde a prática foi realizada era denominada de Totalidade $2^{1}$, sendo que corresponde do $3^{\circ}$ ao $5^{\circ}$ ano. Possuía doze alunos regularmente matriculados, embora nove eram assíduos, sendo três do sexo feminino e seis do sexo masculino, todos residentes no bairro, próximos à escola. As idades da maioria dos alunos situavam-se entre 14 e 20 anos, sendo a aluna com maior idade de 66 anos. Dois alunos da turma eram considerados "especiais", por apresentarem grandes dificuldades de aprendizagem.

A partir da realidade observada na turma de estágio, procurou-se responder à pergunta: como tornar a EJA num espaço de transformação dos educandos em sujeitos protagonistas do seu aprender? Buscando transformar o espaço da sala de aula, a metodologia utilizada foi o trabalho com Projeto de Aprendizagem (PA), com a temática da "Identidade", construída coletivamente com os educandos, que resultou numa experiência em que os alunos eram o foco central de trabalho, tornando-os ativos em suas aprendizagens. $\mathrm{O}$ reconhecimento do processo de aprendizagem como dinâmico e ativo (HARA, 1992), permite que o situemos como um ato de conhecimento.

Por todo exposto, este o presente artigo tem por objetivo descrever e analisar a prática desenvolvida no Estágio Supervisionado, etapa obrigatória do PEAD, realizado numa turma de EJA no período noturno, cujo PA desenvolvido teve como foco os estudantes, mediatizado pelo uso da tecnologia, tornando-os ativos e participativos no processo de construção de conhecimentos e de desenvolvimento enquanto sujeitos. O espaço da sala de aula foi transformado num ambiente dinâmico, participativo e colaborativo contribuindo para mostrar novos horizontes à Educação de Jovens e Adultos.

\section{Pressupostos teóricos}

O Projeto de Aprendizagem (PA) constitui-se numa metodologia/pedagogia de práticas, cujo foco propõe a autonomia dos alunos em práticas de pesquisa. É possível desenvolver o PA com diferentes turmas, idades e modalidades, respeitando o tempo e espaço de cada aluno. Na prática, envolve em uma metodologia ativa, em processo, que não exige seguir etapas rígidas; à medida em que o trabalho vai sendo desenvolvido as interlocuções e etapas vão acontecendo. Há diferentes maneiras de trabalhar com os alunos e produzir

\footnotetext{
1 Até o início do estágio, a turma era atendida de forma multisseriada, sendo que a professora titular também leciona para a Totalidade 1 , equivalente ao $1^{\circ}$ e $2^{\circ}$ anos, com cinco alunos matriculados.
} 
conhecimento: debate, estudo, experimentação, jogos, material concreto, tecnologias, trabalho com projetos de aprendizagem, sempre partindo da curiosidade.

A situação de projeto de aprendizagem pode favorecer especialmente a aprendizagem de cooperação, com trocas recíprocas e respeito mútuo. Isto quer dizer que a prioridade não é o conteúdo em si, formal e descontextualizado. A proposta é aprender conteúdos, por meio de procedimentos que desenvolvam a própria capacidade de continuar aprendendo, num processo construtivo e simultâneo de questionar-se, encontrar certezas e reconstruí-las em novas certezas. Isto quer dizer: formular problemas, encontrar soluções que suportem a formulação de novos e mais complexos problemas. Ao mesmo tempo, este processo compreende o desenvolvimento continuado de novas competências em níveis mais avançados, seja do quadro conceitual do sujeito, de seus sistemas lógicos, seja de seus sistemas de valores e de suas condições de tomada de consciência. (FAGUNDES, SATO, MAÇADA, s.d. p. 24).

A vontade de aprender, de colaborar, de buscar fonte para que se possa trabalhar com o tema do projeto, demonstra claramente uma nova significação do aprender. Fagundes, Sato e Maçada (s.d., p.16) alertam que é fundamental que a questão a ser pesquisada parta da curiosidade, das dúvidas, das indagações do aluno, ou dos alunos, e não imposta pelo professor. Isto porque a motivação é intrínseca, é própria do indivíduo. O trabalho com PA na EJA possibilita ampliar as possibilidades de interação e participação dos estudantes, para ultrapassarmos as práticas tradicionais desenvolvidas nesta modalidade, motivando-os a persistirem e serem frequentes às aulas, tornando-as atrativas, participativas, desafiadoras.

A metodologia de trabalho com PA requer uma atenção e planejamento do professor e, embora haja um planejamento para sua realização, o andamento do mesmo reserva muitas surpresas e momentos que enriquecem a aprendizagem, além de constantes trocas entre os alunos. O foco da ação passa a ser os alunos, que têm papel ativo na pesquisa. Os professores devem ser os mediadores nesse processo de construção do conhecimento, encorajando os alunos a buscarem, serem questionadores, terem prazer de aprender e saber porque e para que serve o que estão aprendendo. Fagundes, Sato e Maçada (s.d., p.16) explicam que

[...] Quando o aprendiz é desafiado a questionar, quando ele se perturba e necessita pensar para expressar suas dúvidas, quando lhe é permitido formular questões que tenham significação para ele, emergindo de sua história de vida, de seus interesses, seus valores e condições pessoais, passa a desenvolver a competência para formular e equacionar problemas. Quem consegue formular com clareza um problema, a ser resolvido, começa a aprender a definir as direções de sua atividade. 
O professor passa do papel de transmissor para mediador do conhecimento, no qual os alunos têm participação ativa na pesquisa, discussão e troca de ideias. O aprendizado é compartilhado - um aprende com o outro.

[...] A competência do aluno para formular e equacionar problemas se desenvolve quando ele se perturba e necessita pensar para expressar suas dúvidas e quando lhe é permitido formular questões que lhe sejam significativas, pois emergem de sua história de vida, de seus interesses, seus valores e condições pessoais. (FAGUNDES, SATO, MAÇADA, sd. p.19).

A escolha do tema identidade partiu das inquietações dos próprios estudantes, possibilitando-lhes maior engajamento em relação às suas aprendizagens. A proposta de trabalhar com a identidade e realidade dos educandos deu sentido aos processos de pesquisa, estudos, uma vez que eles se sentiram envolvidos e o contexto teve significado para eles, possibilitando uma leitura do "seu mundo".

Olhar e pensar a EJA implica em tecer pressupostos da teoria de Paulo Freire (1996) para a importância da Educação de Jovens e Adultos no processo de empoderamento dos sujeitos e transformação social do nosso país. Um conceito muito importante da teoria de Freire, o empoderamento, constitui num ato social e político. Relacionado à potencialidade criativa e, ao mesmo tempo, ao desenvolvimento e potencialização das capacidades dos sujeitos.

[...] Mesmo quando você se sente, individualmente, mais livre, se esse sentimento não é um sentimento social, se você não é capaz de usar sua liberdade-recente para ajudar os outros a se libertarem através da transformação da sociedade, então você só está exercitando uma atitude individualista no sentido do empowerment ou da liberdade. (FREIRE, 1996, p. 135).

Freire e sua teoria são profundamente otimistas. Ele defende a possiblidade e necessidade da mudança na escola, uma vez que ela tem importante papel na transformação social. Esta mudança é ao mesmo tempo política e pedagógica, pois a escola é um lugar de luta e de esperança; por isso, deve ser de qualidade e para todos.

A EJA assume papel central neste processo, uma vez que seu público-alvo tem característica e história próprias, precisam ser considerados no processo, transpondo os limites da simples condição de espaço de aprender para um espaço de transformar.

A Pedagogia de Freire propõe uma educação humanista-libertadora, com base no diálogo e na dialogicidade, categorias centrais de um projeto pedagógico crítico. Neste 
sentido, é forma propulsora do pensar crítico-problematizador, uma práxis social comprometida com o processo de humanização, que deve ser o eixo das ações na EJA. Freire (1993) propõe um projeto de alfabetização em permanente diálogo com a realidade dos educandos, com base na ação-reflexão-ação sobre a ação práxiológica docente, sobre as relações, limites e potencialidades da teoria colocada na prática. Para ele, o processo de alfabetização é um ato de conhecimento, de leitura do mundo, em que a práxis pedagógia adquire um papel político. A Pedagogia de Freire implica num projeto educacional e sociopolítico com vistas à mudança social, à autonomia e ao empoderamento social, mediante a leitura do mundo, o acesso à palavra.

Para que isso ocorra, é fundamental que a sociedade brasileira compreenda a finalidade da escola pública, principalmente no momento político em que vivemos no Brasil, em que a democracia e as políticas públicas educacionais estão fortemente ameaçadas e sucateadas. Faz-se necessária a recuperação do sentido e da função da escola pública, como esfera pública de participação democrática, envolvendo as comunidades escolares, fazendo análise de conjuntura, promovendo instâncias dialógicas e práticas participativas e inclusivas, perspectivando as mudanças sociais que desejamos.

Educar é um ato político que permite às pessoas o acesso ao conhecimento da sua realidade, de seus direitos, de suas potencialidades. Para isso, é necessário desenvolver uma pedagogia libertária que veja a escola como um espaço de cultura, que planeje a escuta e a identificação dos saberes de todos. Isso possibilitará a compreensão de que realizar o projeto pedagógico numa escola é realizar um projeto político, com práticas de cidadania.

Outro aspecto que merece relevância foi o uso das tecnologias da informação e comunicação (TICs), ferramentas que possibilitaram a curiosidade e um ambiente interativo e desafiador para os estudantes. As TICs ainda são pouco exploradas nas escolas públicas, principalmente na EJA. De acordo com a pesquisa TIC Educação 2018, realizada pelo Centro Gestor da Internet do Brasil por meio do Centro Regional de Estudos para o Desenvolvimento da Sociedade da Informação, mostra que $98 \%$ das escolas urbanas têm ao menos um computador com acesso à internet e que $62 \%$ das escolas rurais não têm computador para uso dos alunos; somente $43 \%$ do total de alunos faz uso das tecnologias nas escolas como ferramentas para aprendizagem. 
As TICs apresentam um universo de possibilidades de uso pedagógico em sala de aula, possibilitando ao mesmo tempo interatividade e interconectividade (FAGUNDES, SATO; MAÇADA (s.d.). As autoras alertam:

[...] A grande maioria das metodologias educacionais, e de suas tecnologias, que atualmente são ensinadas nos cursos de formação de professores, mostram-se ineficientes para ajudar o aluno a aprender e desenvolver novos talentos. Não se sabe ajudá-lo a alcançar o poder de pensar, de refletir, de criar com autonomia soluções para os problemas que enfrenta.

Pelo exposto, urge a necessidade de revisitarmos as práticas da EJA, no sentido de propiciar um maior protagonismo dos sujeitos, reconfigurando o espaço da sala de aula, explorando novas ferramentas, aliadas às TICs, garantindo à todos o acesso, a permanência e o sucesso escolar. É hora de dar voz e vez aos sujeitos da EJA, valorizando esta modalidade e pagando nossa dívida histórica com relação à oferta e qualidade que merece.

O Plano Nacional de Educação (PNE, BRASIL, 2014) traça importantes diretrizes e metas com relação à EJA. Além de estabelecer como diretrizes a erradicação do analfabetismo; a universalização do ensino; a superação das desigualdades educacionais e a melhoraria da qualidade da educação; entre outras, ao longo de suas metas são estabelecidas diversas estratégias que visam garantir acesso a esta modalidade de ensino. Por fim, cabe destacar a meta 10 e suas onze estratégias, tratam especificamente da oferta da EJA aliada à educação profissional, em nosso plano decenal, cuja vigência encerra no ano de 2024.

[...] Há que se preocupar com o cidadão que busca a EJA nos diferentes espaços, tanto na cidade, como no meio rural, pois as formas de ensinar se constituem em desafios, considerando o compromisso social e profissional com a comunidade. (FRIEDRICH et. al. 2010, p. 404)

\section{Análises e discussões sobre a pedagogia do Projeto de Aprendizagem}

Durante os meses de setembro e outubro de 2018 realizou-se o acompanhamento da rotina da EJA, a fim de conhecer a escola, sua estrutura, funcionamento e as práticas ali desenvolvidas. Esta oportunidade apontou desafios, uma vez que a professora unidocente, nas turmas dos Anos Iniciais, desenvolvia uma prática completamente tradicional, com o uso do quadro e caderno, exclusivamente, em função do atendimento de mais de uma turma na mesma sala de aula. Além disso, havia pouca ou quase nenhuma interação entre os estudantes, que deveriam copiar as atividades, resolvê-las para em seguida, a professora corrigi-las. 
Neste contexto, desenvolver a metodologia do PA já apresentava um desafio inicial, de romper aquela estrutura tradicional que prevalecia, buscando a interação e participação ativa dos estudantes, que até então não aconteciam.

O acompanhamento anterior da turma foi fundamental para o planejamento do tema a ser desenvolvido no PA, porque surgiu a partir de uma atividade proposta pela professora titular, inicialmente com objetivo único de uma produção escrita, visando estimular o potencial dos alunos. Foi assim, que surgiu o tema "Identidade", com o qual passamos a trabalhar ao longo da prática docente, de outubro a dezembro daquele ano.

Por este motivo, ao iniciar a prática, foi necessário esclarecer aos alunos a metodologia a ser utilizada e o tema escolhido, sugerida por eles mesmos a partir das observações anteriores, por meio de atividade proposta pela professora titular através da atividade "Se eu fosse", que gerou muitas indagações, curiosidades e posicionamentos dos alunos.

Como atividade inicial, os alunos se apresentaram informando seu nome, local do bairro onde moravam e o que mais quisessem falar sobre si mesmos. Concluída esta parte, receberam uma folha com o título "Quem sou eu..." com a imagem de uma digital, tendo por objetivo introduzir a atividade, em que cada um deveria preencher informações sobre sua vida. Todos os alunos conseguiram realizar a atividade. Alguns apresentaram mais proficiência escrita e textual, já outros solicitavam auxílio na escrita e na expressão de algumas palavras. A atividade motivou-os muito, pois se entusiasmaram em construir uma narrativa sobre seus lugares de moradia e sobre si mesmos. A última atividade propunha elaborar um autorretrato, em que cada aluno, partindo da sua descrição, registrasse através de desenho como enxergava a si próprio. Como não havia espelho na sala, utilizamos o celular e a câmera, para que os alunos com dificuldades pudessem se observar e fazer o seu autorretrato.

Seguindo, cada um se descreveu para os demais e apresentou o autorretrato produzido. Alguns alunos tiveram muitas dificuldades em informar o nome da rua em que residia, fato que foi solucionado por meio do auxílio dos próprios colegas, que os conhecem e sabem onde residem. Os colegas também contribuíram na apresentação dos que conheciam e cada um teve de falar aspectos sobre os demais, quando puderam perceber semelhanças e diferenças entre seus modos de vida e o dos colegas. Outro aspecto trabalhado foi a escola, a motivação que levou cada um dos estudantes a procurar a EJA e retornar os estudos. 
Assim, a primeira semana, constituiu o trabalho com as metas iniciais do Projeto de Aprendizagem, que consistiram em fazer levantamento de questões de interesses dos alunos, a escolha do tema do PA a ser desenvolvido (meta 1), bem como levantamento das certezas, dúvidas e informações prévias acerca do tema escolhido (meta 2).

Para além das dificuldades iniciais, foi um momento muito rico de interação em sala de aula, face às várias curiosidades dos alunos e a vontade que eles tinham de conhecer mais seus colegas. As práticas desenvolvidas no PA evidenciaram a motivação e o envolvimento dos alunos com as propostas, pois além de se envolverem e realizarem as atividades, buscavam e traziam para as aulas mais informações e materiais relativos ao tema do projeto: informações sobre o bairro e familiares, sobre si mesmos, sobre suas preferências, identificações, gostos etc. Cabe destacar que, até então, os alunos estavam acostumados a trabalhar individualmente, sem nenhuma interação com os colegas. Desde o início do planejamento da prática, após a observação preliminar, buscamos organizar o PA no sentido de integrar os alunos, visando explorar diversas formas de interação e colaboração.

Outra atividade propositiva foi a de configurar parte da sua constituição histórica familiar, por meio da árvore genealógica. Tiveram facilidade em registrar seu nome e dos pais, porém dos avós paternos e maternos gerou maiores dificuldades, o que necessitou fazerem uma consulta aos seus pais em casa (parte dos alunos não tem o documento da certidão de nascimento na escola, substituído pela carteira de identidade, pois foi um documento que consultamos para realizar a atividade).

Concluída esta etapa, passamos a outro objetivo que era se conhecer e reconhecer em espaços distintos. Foram realizadas atividades de localização no espaço, com a utilização de mapas do Brasil, Rio Grande do Sul, Porto Alegre, localização do bairro onde residem, necessitando de uma orientação clara do professor sobre a conceituação de país, estado, município e bairro, que são conceitos que os alunos costumam confundir frequentemente. A utilização do mapa político do Brasil foi imprescindível para a compreensão dos diferentes espaços, bem como, a relação de pertencimento a diferentes tipos de espaços. De modo semelhante, apoiados no mapa do Rio Grande do Sul, com o objetivo de localização do município como parte do território do estado e, concluindo, explorando o mapa da cidade, compreendendo que está dividida em regiões, denominadas como bairros. O objetivo era a localização do bairro onde residiam, situando-os espacialmente dentro da cidade. 
Esta parte foi consolidada por meio da utilização do laboratório de informática da escola, pouco ou quase nada utilizado pelos professores e alunos da EJA na escola. A atividade que foi desenvolvida, utilizando o google maps, objetivava que cada aluno deveria localizar sua casa e traçar o trajeto que faz todos os dias da casa para a escola. Após, utilizando a ferramenta que permitiu que explorassem a rua, "andando" da sua cada até a escola no caminho que fazem todos os dias; cada aluno também mostrou em que rua estava sua casa, inclusive mostrando a própria casa para os demais.

Outra atividade que realizamos foi a busca de imagens do bairro utilizando o google imagens. Eles chegaram à conclusão, por meio da conversa que estabelecemos, de que nas imagens encontradas só apareciam alagamentos nas ruas e "paredão" (expressão que usam para designar a presença da polícia em busca de bandidos, drogas e mortes ocorridas). $\mathrm{O}$ mesmo aconteceu com as notícias encontradas, somente de enchentes e envolvendo acontecimentos policiais. As análises sobre o predomínio dessas imagens e notícias foram muito interessantes, pois os alunos deflagraram processos de ordem social e estrutural que configuram o bairro, tais como os processos de opressão sofridos, a violência policial, condições de classe, contextos de precarização e vulnerabilidades.

Em contraposição, trabalhamos os aspectos positivos do bairro, listados por eles, destacando bons espaços de convivência como praças e parques, com destaque para os três principais pontos de convivência do bairro, que foram localizados com o uso do google maps. Sobre notícias de aspectos positivos do bairro, os alunos desconheciam. Então, apresentamos ações relacionadas à associação de moradores, que anualmente, em novembro, realizam um jantar-baile para arrecadar dinheiro que é utilizado no Natal para compra e distribuição de brinquedos para crianças carentes do bairro, o que foi elogiado por todos, pois desconheciam essa ação. Aprovaram a iniciativa e chegaram à conclusão de que deve haver outras boas notícias, mas que infelizmente não são divulgadas.

A utilização do laboratório de informática passou a ser parte esperada das aulas, já que o estranhamento inicial havia sido vencido, pois residia no desconhecimento do uso da tecnologia e a forma de manusear o computador e a internet. As aprendizagens construídas nesta aula foram consolidadas para ações que tiveram sentido, significado para os estudantes, que por meio da tecnologia exploraram o mundo real, onde vivem, se reconhecendo sujeitos pertencentes a um bairro e comunidade. 
A cada semana de prática na EJA, novos sentimentos, inspirações, novas aprendizagens surgiam em minha carreira docente. O fazer pedagógico tornou-se algo com sentido, pois além da interação com os alunos, a execução do planejamento das atividades, existe tudo aquilo que não estava previsto no planejamento, uma vez que o mesmo não é rígido. Em nossas trocas, diálogos, uns aprendemos com os outros. Como morava no mesmo bairro onde atuava, assim como meus alunos, aprendemos juntos sobre este espaço, suas dificuldades, potencialidades, bem como, sobre os sujeitos/alunos que frequentam a EJA. Nas conversas formais e informais, que surgiram em nossas interações, se fundaram as relações de conhecimento e confiança. Por meio delas pudemos conhecer um pouco mais de cada um, suas origens, dia-a-dia, suas aspirações e desejos, alcançando os objetivos previstos no PA que estava sendo desenvolvido.

Ao longo desta caminhada, já estávamos desenvolvendo a meta 3 , relativa à realização das atividades previstas para essa etapa. Outra atividade realizada também representou uma gama de aprendizagens para todos. Destacamos a uma simples atividade, pensada como parte do PA "Identidade", que resultou no convite à vice-diretora do turno da tarde, que atua há mais de 40 anos na escola. O objetivo da atividade, do convite, era relatar aos alunos o histórico da escola, passando pela escolha do nome, das mudanças ocorridas no seu espaço, número de alunos, professores e contar aspectos que constituem o histórico da escola no bairro. A atividade foi além do espaço da sala de aula e da própria escola, abrangendo inclusive a história do bairro. Houve grande interesse e participação dos alunos, já que muitos familiares estudaram na escola. A vice-diretora nos contou sobre a primeira sede da escola, que ficava em outro local do bairro, cuja mudança ocorreu em função do crescimento do bairro e do aumento do número de famílias. O espaço atual era antes uma praça, que foi cedida pela prefeitura ao estado, onde havia um banhado, sendo que nos primeiros anos, a cada chuva, todo o pátio alagava. As primeiras construções eram as famosas "brizoletas" (de madeira, típicas do governo Brizola). Mas a surpresa da conversa, foi que no meio de todo o percurso, surgiu à explicação sobre as origens dos nomes das ruas e do próprio bairro, em homenagem aos heróis inconfidentes e à rainha Elizabeth.

Assim, esta conversa, além de atender a um objetivo inicial do projeto "Identidade" sobre a escola e seu espaço no bairro, nos ajudou a entender a constituição do espaço do próprio bairro e da origem da designação das ruas, que até então desconhecíamos. Visitamos todos os espaços da escola, incluindo as salas e área física, que é muito ampla. Soubemos das 
mudanças que ocorreram na infraestrutura da escola e dos projetos futuros para utilização e aproveitamento do espaço, cuja necessidade é construção de uma quadra coberta, com iluminação, para oferta de mais um espaço para os alunos, incluindo a EJA e para a prática de esportes e atividades físicas, que atualmente não ocorrem no turno da noite por falta de espaço adequado e iluminação.

Também desenvolvemos atividades voltadas ao conhecimento e compreensão da realidade da escola. Partimos de um diálogo retomando um pouco da história da escola, mais os conhecimentos que os próprios alunos possuíam da história da escola e as mudanças que observaram ao longo do tempo. Os alunos apontaram a importância da escola para o bairro e suas famílias, já que diversos familiares passaram por ali, mesmo muitos não tendo concluído o Ensino Fundamental. A escola é uma referência e todos se lembram dela e de seus professores com carinho.

Também analisaram as principais dificuldades que ainda persistem como a falta de professores, os poucos recursos para manutenção da escola, a violência no entorno, dentre outros aspectos. Ao concluirmos esta parte, foi realizada a construção de um texto coletivo, registrando os principais aspectos da história da escola, bem como, seu significado para a turma, destacando os aspectos que tornam a escola uma referência e as dificuldades que precisam ser superadas. É importante registrar que na conversa sobre a escola, apesar de todas as dificuldades apresentadas, é uma importante referência para cada um dos estudantes, pois percebem ligação com sua história de vida e com a de suas famílias.

Nesta fase, já nos encontrávamos sistematizando as aprendizagens construídas ao longo do nosso projeto. Ao longo do semestre, diversas atividades fins foram realizadas com os alunos da EJA visando contemplar as ações previstas no PA que estava sendo desenvolvido. Produções de texto, visando organizar as narrativas e construções realizadas foram fundamentais para sistematizar as aprendizagens construídas no coletivo da turma. Além disso, o que mais enriqueceu todo o processo foram as constantes interações/diálogos estabelecidos entre nós, partícipes deste ambiente de trocas/aprendizagens, vislumbrando novos rumos e possibilidades para a vida de cada um, bem como de superação de desafios.

Ficou evidente a evolução dos sujeitos da EJA mediante o uso da proposta do PA como metodologia de trabalho, atingindo os objetivos propostos. Ao final, todos os alunos que estavam frequentando foram promovidos para a etapa seguinte, superando suas dificuldades, estabelecendo novas metas e objetivos em suas vidas. 
Há de se destacar a importância do uso contínuo das tecnologias como recurso mediador das aprendizagens, habituando os alunos ao seu uso e domínio de alguns dos seus recursos básicos, uma vez que até então não faziam uso das TICs em sala de aula. As TICs

podem ajudar a enriquecer os ambientes de aprendizagem, podem ampliar os espaços das salas de aula, podem vencer as barreiras do tempo, podem servir como "próteses" cognitivas, podem ajudar a ampliar os processos socioafetivos e a conscientização, podem ajudar a atender os aprendizes como verdadeiros sujeitos de sua aprendizagem, podem assegurar a intercomunicação coletiva, podem ajudar a criar comunidades de aprendizagem e desenvolvimento. (FAGUNDES, SATO, MAÇADA, s.d., p. $14)$.

O trabalho com o PA possibilitou transformar os alunos, de sujeitos passivos a ativos em seu processo de construção de conhecimentos, reconhecendo em si mesmos as capacidades e habilidades, dotados de potencialidades, desenvolvendo em maior autonomia, responsabilidade e dedicação. Além disso, permitiu o estabelecimento de vínculos entre os sujeitos, que passaram a desenvolver um trabalho mais colaborativo e dotados da capacidade de se reconhecer parte e todo de um grupo.

Todo o trabalho foi desenvolvido a partir da criação de vínculos, superando as velhas contradições da EJA, mostrando que novos horizontes são necessários.

\section{Considerações finais}

No presente artigo buscamos apresentar uma experiência docente na Educação De Jovens e Adultos, lançando inicialmente o questionamento sobre como tornar a EJA um espaço de transformação dos sujeitos em protagonistas do seu aprender. Buscou-se, mediante reflexões acerca da prática de estágio realizado numa turma de EJA, mediatizados pelo uso da tecnologia e da metodologia do Projeto de Aprendizagem (PA), transformar a sala de aula de um ambiente passivo, num espaço dinâmico de trocas, de interações, de colaboração e interação contínuas. O objetivo foi o de propiciar aos sujeitos experiências de autonomia e participação ativa no processo de construção de conhecimentos.

Ao final, da análise realizada no decorrer da prática, podemos afirmar que o uso do PA possibilita ao docente tornar sua prática mais rica, mais dinâmica, desafiando os alunos constantemente, tornando-os colaborativos e participativos em todo o processo de construção das aprendizagens. Observando a realidade dos alunos ao iniciar o Estágio Supervisionado, e comparando com o final do processo, constatamos que uma transformação foi provocada no 
espaço da sala de aula. Transformação esta, que além de dinamizar as relações, estimulou que o ambiente se tornasse um espaço constante de trocas, dando voz e vez a todos os estudantes.

Ao trabalhar o PA com o tema "Identidade", cujo foco era cada aluno reconhecer-se como sujeito dotado de uma identidade própria, identificando suas origens, características, potencialidades, reconhecendo-se como pertencentes a uma comunidade e suas possibilidades de transformação pessoal. Todo foco do PA e as atividades desenvolvidas, deram protagonismo aos sujeitos da EJA, tornando-os ativos durante todo o processo de construção do conhecimento. Todas as ações foram planejadas e executadas pensando nos alunos como partícipes.

O professor passa do papel de transmissor para mediador do conhecimento, pois os alunos têm participação ativa na pesquisa, discussão e troca de ideias. O aprendizado é compartilhado - um aprende com o outro.

Quando faz sentido é mais prazeroso e fácil de aprender. Devemos, enquanto docentes, ser sempre mediadores da aprendizagem: estimular/provocar os alunos, vincular os conhecimentos ao seu cotidiano para que entendam que tudo tem um significado. É importante que estejamos atentos para analisar e refletir sobre o nosso aluno, o ambiente em que ele está inserido, a fim de questioná-los e consequentemente, aprofundarmos as pesquisas que estão sendo feitas. Com isso, permite-se a interação e a autonomia e a capacidade de pensar e de construir o seu saber a partir da reflexão sobre a prática, sobre a realidade, sobre o entorno, os espaços do sujeito.

Desta forma, se observa que a motivação e interesse dos alunos nos projetos desenvolvidos vão além do trabalho que normalmente desenvolvemos em sala de aula. Como os temas surgem dos interesses dos próprios alunos, percebe-se que a aula passa a ter mais sentido, significado. A vontade de aprender, de colaborar, de buscar fontes para que se possa trabalhar com o tema do projeto, demonstra claramente uma nova significação do aprender.

Assim como Freire (1996) nos ensina, educar é um ato político, de empoderamento dos sujeitos. E é assim que devem ser as práticas na EJA, dotando os sujeitos de autonomia, responsabilidades e respeitando suas individualidades.

A prática mostrou que a EJA carece urgentemente de novas práticas e espaços. Para isso, há necessidade de se repensar a formação de professores no âmbito das Instituições de Ensino Superior, para que se lance um olhar sobre os sujeitos que ali estão, considerando-os na práxis docente, por isso “[...] o sujeito educador, precisa de uma sólida formação política e 
social, para atuar frente às propostas pedagógicas incoerentes com o contexto em que se desenvolvem os programas de EJA" (FRIEDRICH, et. al. 2010, p.404).

Ainda, urge a necessidade de novas políticas públicas com mais atenção à EJA e as condições ofertadas no país, ultrapassando velhas práticas tradicionais de ensino e falta de infraestrutura adequada. O Plano Nacional de Educação (PNE), atualmente em processo de esvaziamento por parte do governo federal, para o qual a educação é inimiga do desenvolvimento do país, é política fundamental que deve(ria) garantir o espaço que a EJA merece no Brasil.

Assim, podemos afirmar que o trabalho com a metodologia do PA se mostrou uma experiência exitosa, tendo como ponto de partida os sujeitos, suas histórias e o desenvolvimento do sentimento de pertencimento, além das possibilidades que se deram, a partir de sua formação enquanto cidadãos. A utilização das TICs propiciou experienciar novas vivências, dando mais sentido ao processo de construção do conhecimento e de crescimento dos sujeitos.

\section{Referências bibliográficas}

BRASIL. Lei no 13.005, de 25 de junho de 2014. Aprova o Plano Nacional de Educação PNE e dá outras providências. Disponível em: <http://www.planalto.gov.br/ccivil_03/_ato2011-2014/2014/lei/113005.htm>. Acesso em: 10 jun. 2019.

BRASIL. Lei $\mathbf{n}^{\mathbf{0}} \mathbf{1 3 . 6 3 2}$, de 6 de março de 2018. Altera a Lei no 9.394, de 20 de dezembro de 1996 (Lei de Diretrizes e Bases da Educação Nacional), para dispor sobre educação e aprendizagem ao longo da vida. Disponível em: < http://www.planalto.gov.br/ccivil_03/_Ato2015-2018/2018/Lei/L13632.htm>. Acesso em: 10 jun. 2019.

BRASIL. Ministério da Educação. Parecer CNE/CEB no 11/2000. Diretrizes Curriculares Nacionais para a Educação de Jovens e Adultos. Disponível em: 〈http://portal.mec.gov.br/cne/arquivos/pdf/PCB11_2000.pdf >. Acesso em: 10 jun. 2020.

COMITÊ GESTOR DA INTERNET NO BRASIL. TIC Educação 2018. Disponível em: < https://cetic.br/pesquisa/educacao/indicadores/>. Acesso em: 01 jun. 2020.

FAGUNDES, Léa da Cruz; SATO, Luciane Sayuri; MAÇADA, Débora Laurino. Aprendizagens do futuro: as inovações começaram. Coleção Informática para a mudança na Educação. Brasília: MEC, s/d.

FREIRE, Paulo. Pedagogia da autonomia: saberes necessários à prática educativa. 1. ed. São Paulo: Paz e Terra, 1996. 
FREIRE, Paulo. Pedagogia do oprimido. São Paulo: Paz e Terra, 1993.

FRIEDRICH, Márcia; et. al. Trajetória da escolarização de jovens e adultos no Brasil: de plataformas de governo a propostas pedagógicas esvaziadas. Ensaio: Avaliação e Políticas Públicas em Educação. Rio de Janeiro: v. 18, n. 67, p. 389-410, abr./jun. 2010.

HARA, Regina. Alfabetização de adultos: ainda um desafio. 3. ed. São Paulo: CEDI, 1992. MINISTÉRIO DA EDUCAÇÃO. Parecer CEB/CNE 11/2000. Diretrizes Curriculares Nacionais para a Educação de Jovens e Adultos. Disponível em: < http://portal.mec.gov.br/cne/arquivos/pdf/PCB11_2000.pdf >. Acesso em: 24 jun. 2019.

PAIVA, Jane; FERNANDES, Fátima Lobato. Da concepção à prática de formação inicial: a EJA no currículo de pedagogia. Revista Teias. Rio de Janeiro: vol. 17, Edição especial, p. 2542, 2016. 